\title{
PYROPROCESSING FLOWSHEETS FOR RECYCLING USED NUCLEAR FUEL
}

\author{
M.A WILLIAMSON* and J.L. WILLIT \\ Argonne National Laboratory \\ Argonne, IL USA \\ "Corresponding author. E-mail : williamson@anl.gov
}

Received July 28, 2011

Two conceptual flowsheets were developed for recycling used nuclear fuel. One flowsheet was developed for recycling used oxide nuclear fuel from light water reactors while the other was developed for recycling used metal fuel from fast spectrum reactors. Both flowsheets were developed from a set of design principles including efficient actinide recovery, nonproliferation, waste minimization and commercial viability. Process chemistry is discussed for each unit operation in the flowsheet.

KEYWORDS : Pyrochemical Processing, Nuclear Fuel Reprocessing, Electrochemical Processing

\section{INTRODUCTION}

Argonne National Laboratory has a longstanding history in the development of pyroprocessing flowsheets for recycling actinides from used nuclear fuel. The experience extends from the 1950s in which methods were developed to recycle actinides contained in used fuel from the Experimental Breeder Reactor II via the melt refining process to the present day activities in support of the U.S. Department of Energy's, Fuel Cycle Research and Development Program (1-2).

Between those activities was the development of fuel recycling technologies for the Integral Fast Reactor (IFR) (3). This conceptual nuclear system consisted of several (e.g., four to six) liquid-metal cooled fast neutron spectrum reactors collocated with a used fuel recycling facility to allow for short turnaround fuel reprocessing and on-site waste management. One of the many significant breakthroughs developed during the IFR program was the use of electrochemical processes to accomplish the chemical separations rather than earlier processes that made extensive use of reagents. This feature was a major step toward waste minimization in used fuel recycling. Use of electrochemical processes in recycle systems continues in the present day work.

Although the IFR program was cancelled in 1994, the main component of the fuel recycling technology, uranium electrorefining, was demonstrated as part of the Experimental Breeder Reactor II fuel-conditioning program (4). This program demonstrated the feasibility of recovering uranium from used nuclear fuel by electrochemical methods and the operation of the electrochemical process equipment in a hot-cell environment.

Our flowsheet development efforts build from these past experiences and design principles such as actinide recovery and waste minimization to address the general requirements of today's fuel recycling system. This paper describes the flowsheets developed for recycling used nuclear fuel from light water reactors (LWR) and fast reactors (FR).

\section{DESIGN PRINCIPLES}

Although there are a number of design principles for developing used nuclear fuel recycling flowsheets, the following components are essential to flowsheet development - efficient actinide recovery, strong nonproliferation features, waste minimization, and commercial viability.

Actinide recovery must be highly efficient, for example $99.9 \%$, throughout the recycling process so that minimal actinides are lost to the process waste stream. Recovery of the actinides and, more importantly, the transuranic elements at this level reduces the radiotoxicity of the waste materials to a value lower than that of the original uranium ore within a period of 1000 years. In addition, actinide recovery at the $99.9 \%$ level reduces the long-term heat load to the waste stream by a factor of approximately 1000. It is also important that high recovery efficiencies 
are achieved in a manner that is not overly complex or leads to extensive recycle streams.

Closely coupled with efficient actinide recovery is the need to address the non-proliferation characteristics of the recycle system. Our flowsheets are designed to yield a co-deposit of uranium and transuranic elements instead of pure streams of each transuranic element. This approach reduces the desirability of material in the process since additional separations processes are required to achieve a pure elemental product. Although designing a process with a co-deposited actinide product is key, it is not sufficient to meet non-proliferation objectives. It is necessary to design a system that is safeguardable so that material diversion can be easily detected and materials accountancy can be seamlessly integrated into the system.

Flowsheets must also be designed to yield a minimum amount of process waste while providing the desired recycle products and durable waste materials. In this regard, one of the most important features of a pyroprocessing flowsheet is the use of electrochemical processes. These processes rely on external power sources and electrodes to achieve the desired chemical separations rather than a chemical reagent, which eliminates the need for reagentrecycle systems. In addition to minimizing the use of chemical reagents, flowsheets designed to recycle the bulk of the process salt rather than combining it with the fission product waste significantly reduces the amount of waste discharged to a repository. This approach allows for efficient use of repository space and could reduce the cost of the disposal system.

Finally, the flowsheet must be designed so that the fuel recycle process can be operated on an industrial scale. Each of the unit operations must be easily integrated with the up- and downstream operation to provide for efficient material transfers. The process must be designed to take advantage of not only the main but also the secondary features of the products from each operation to maximize process efficiency. Process chemistry must be robust and allow straightforward methods for recovery from process upsets. Equipment must scalable, uncomplicated and easily maintained in a remote environment.

\section{LWR FLOWSHEET}

The conceptual flowsheet for the treatment of used LWR fuel is shown in Figure 1. The flowsheet consists of a series of electrochemical processes to convert the actinides and fission products in the used oxide fuel to a metallic state and then separate the metallic actinides from the fission products. The recyclable products from the treatment process are uranium and a co-deposited uranium - transuranic (TRU) alloy intended for use in a fast reactor. The waste forms produced are a ceramic waste material designed for decay storage (i.e., $\mathrm{Cs} / \mathrm{Sr}$ fission product decay storage) prior to geologic storage and two other high-level waste forms designed for geologic storage - lanthanide borosilicate glass and a noble metal alloy waste form containing Tc. A brief description of each of the process steps for treatment of used LWR fuel follows.

Fuel Chopping - Used light water reactor fuel assemblies are chopped (or shredded) by conventional methods to produce fuel segments approximately one to two inches in length. The fuel segments and ceramic fine materials produced during chopping are collected and transferred to fuel baskets used in the electrolytic reduction process. The fuel assembly hardware (e.g., endplates) is

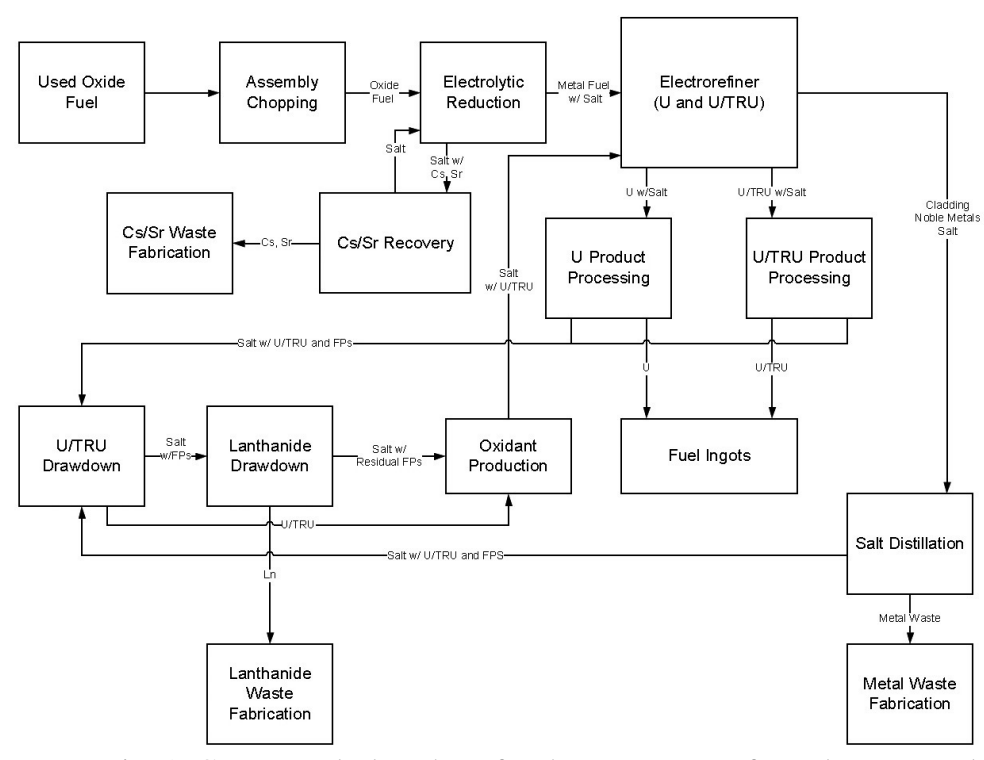

Fig. 1. Conceptual Flowsheet for the Treatment of Used LWR Fuel. 
transferred to metal waste processing. Noble fission gases (i.e., $\mathrm{Xe}$ and $\mathrm{Kr}$ ) released during the chopping process are captured, and the $\mathrm{Kr}$ is separated from the $\mathrm{Xe}$ by cryogenic methods and placed in containers for decay storage. Iodine released during the process is captured in silver impregnated zeolite beds and prepared for geologic disposal.

Electrolytic Reduction - More than a decade ago, we developed an electrochemical process for converting metal oxides to the base metal (5). The fuel oxides, contained in the fuel basket, function as the cathode of the electrochemical cell. An inert material such as platinum or a conductive ceramic functions as the oxygenevolving anode. $\mathrm{A} \mathrm{LiCl}-\mathrm{Li}_{2} \mathrm{O}$ molten salt held at $650^{\circ} \mathrm{C}$ serves as the electrolyte. As current is passed between the anode and cathode, electrons reduce the metal ion of the metal oxide to yield the base metal at the cathode. Simultaneously, oxide ions are released to the molten salt and transported to the anode where they are oxidized to produce oxygen gas that is released from the cell. The half-reactions describing the process are

$$
\begin{aligned}
& \text { Cathode process }- \\
& \mathrm{M}_{\mathrm{x}} \mathrm{O}_{\mathrm{y}}(\mathrm{s})+2 \mathrm{y} \mathrm{e}^{-}=\mathrm{x} \mathrm{M}(\mathrm{s})+\mathrm{y} \mathrm{O}^{2-} \\
& \text { Anode process }- \\
& \mathrm{O}^{2-}={ }^{1} / 2 \mathrm{O}_{2}(\mathrm{~g})+2 \mathrm{e}^{-}
\end{aligned}
$$

where $\mathbf{M}$ is the metal ion to be reduced. Actinide oxides and the bulk of the lanthanide oxides, except those that form extremely stable oxides such as $\mathrm{Y}_{2} \mathrm{O}_{3}$, are reduced to the base metal (6). Alkali and alkaline earth oxides react with lithium chloride to form chloride species that are soluble in the electrolyte salt. Noble metal oxides, if present, are converted to the base metal and remain in the fuel basket with the actinide and lanthanide metals. Iodine contained in the fuel partitions to the salt phase to form an alkali metal iodide. Oxidation products on the cladding are also converted to their metallic state by this process.

Electrorefining - The metallic product from the electrolytic reduction process is transferred to the electrorefining process for recovery of $U$ and a codeposited U/TRU product. In the electrorefiner, the metallic product, contained in the fuel basket, serves as the anode in the electrochemical cell. The electrolyte used in the cell is a $\mathrm{LiCl}-\mathrm{KCl}$ eutectic salt containing approximately $6 \mathrm{wt} \% \mathrm{UCl}_{3}$ at $500^{\circ} \mathrm{C}$. For improved compatibility with the electrolytic reduction step, a $\mathrm{LiCl}$ electrolyte (i.e., with $6 \mathrm{wt} \% \mathrm{UCl}_{3}$ ) can be used in place of the $\mathrm{LiCl}-\mathrm{KCl}$ but the system must be operated at $650^{\circ} \mathrm{C}$. As current is passed between the anode and cathode of the cell, uranium is anodically dissolved at the anode to produce uranium ions that are soluble in the electrolyte. The uranium ions are transported through the molten salt to the cathode where they are reduced to produce metallic uranium. The TRU elements present in the feed material are also anodically dissolved and form transuranic chlorides that are soluble in the electrolyte. Under proper conditions, the TRU chlorides are co-deposited as metals along with uranium at a separate cathode. Thus, the cell has two electrical circuits. The anode reaction for both circuits is anodic dissolution of the electrolytically reduced used fuel. At one cathode only uranium is electrodeposited (a dendritic deposit) and co-deposition of a U-TRU alloy occurs at a separate cathode. The lanthanides present in the feed behave similar to the TRUs, forming soluble chlorides as they are anodically dissolved. However, the cell is operated so that the lanthanides do not deposit on either of the cathodes. Noble metal fission products are not anodically dissolved and thus remain in the basket along with the cladding. Residual actinide and fission product metals contained in the cladding can be electrochemically removed (i.e. anodically dissolved) from the cladding during this process.

Uranium Processing - The dendritic uranium product collected from the electrorefiner may retain up to $15 \mathrm{wt} \%$ electrolyte salt, which contains transuranic and lanthanide chlorides that must be removed prior to uranium recycle. A distillation process, conducted at approximately $800^{\circ} \mathrm{C}$, is used to recover the salt from the dendritic uranium. After salt removal, the uranium is consolidated to an ingot by heating the dendrites to $1200^{\circ} \mathrm{C}$. The consolidated uranium product can be used in FR fuel fabrication or stored for future use. Salt collected during the distillation process is treated in the actinide drawdown process.

U/TRU Processing - The U/TRU product recovered in the electrorefining process has a much lower melting point than pure uranium therefore, separating the adhering electrolyte from the U/TRU metal can be achieved using a lower temperature bottom-pour method. Because the density of the U/TRU product is approximately ten times that of the molten salt, after melting the metal / salt mixture and allowing phase separation to occur, the two phases can easily be separated and poured from the system using a bottom-pour crucible. The U/TRU product is formed into ingots and used in FR fuel fabrication. The salt collected during the process is treated in the actinide drawdown process, which is discussed next. The bottom pour process has a number of advantages for treating TRU-bearing materials as compared to the salt distillation process. For example, a co-deposit with the composition $65 \mathrm{wt} \%$ TRU and $35 \mathrm{wt} \% \mathrm{U}$ has a melting temperature of approximately $700^{\circ} \mathrm{C}$ thus loss of Am by vaporization from the product is negligible and the salt / metal separation remains straightforward. In addition, this process can be operated in a continuous manner therefore improving throughput.

Actinide Drawdown - The salt recovered in the U, U/TRU and metal waste processing (described below) operations is treated by electrolysis to recover the uranium and the transuranic elements. In the electrolysis 
process, sufficient voltage is applied so that the uranium and transuranic ions present in the electrolyte salt are electrodeposited at a cathode and chlorine gas is evolved at an inert anode (e.g., graphite). The process temperature is $500^{\circ} \mathrm{C}$ for the $\mathrm{LiCl}-\mathrm{KCl}$ electrolyte and $650^{\circ} \mathrm{C}$ in the case of a $\mathrm{LiCl}$ electrolyte. A description of the process and results from feasibility tests are provided in reference 7. The electrolysis process can be operated so that all of the actinides (e.g., >99.9\%) and a small amount of the lanthanides (those with reduction potentials near the actinides) are recovered as a metallic deposit on the cathode. The salt-coated metallic deposit recovered from the electrochemical cell is transferred to the oxidant production process (along with the lanthanide-free salt after the lanthanide drawdown discussed below) where it is chlorinated and returned to the electrorefiner.

Lanthanide Drawdown - After completion of actinide drawdown, the bulk of the now U/TRU-free salt is treated in a subsequent electrolysis process to remove the lanthanide fission products. This process can occur in the same process vessel used for actinide drawdown to minimize salt transfer operations. As in the actinide drawdown process, the lanthanide drawdown process yields a solid metallic lanthanide product at the cathode and chlorine gas at the anode. Operation of the cell is identical to the actinide drawdown process except that different deposition potentials are used. The salt discharged from this process contains only residual fission products (e.g., $<0.1 \mathrm{wt} \%$ ) and is recycled to oxidant production and, subsequently, the electrorefiner.

Lanthanide Waste Fabrication - The recovered lanthanide metals are converted to oxides and subsequently combined with glass frit to form a lanthanide borosilicate glass, which is discharged as a high-level waste. The small amount of salt recovered during the metal oxidation process is recycled to the vessels used for electrorefining or electrolytic reduction.

Metal Waste Processing - Noble metal fission products and cladding recovered from the fuel baskets used in the electrorefiner are treated by distillation to recover the residual salt adhering to the materials. The salt is recycled to the actinide drawdown process for actinide recovery. The noble metals are combined with cladding and assembly hardware, and melted at approximately $1700^{\circ} \mathrm{C}$ to form an ingot, which is discharged as a highlevel waste.

Cs/Sr Waste Form Production - Cesium and strontium are recovered from the molten salt used in the electrolytic reduction process by zeolite ion exchange. The molten salt is contacted with zeolite to occlude the cesium and strontium chlorides in the zeolite. Iodine present in the molten salt as an alkali iodide is also captured in the zeolite. The zeolite containing the cesium, strontium and iodine is mixed with glass frit and heated to produce a ceramic waste form. This waste form is held in decay storage to allow for a reduction of decay heat prior to final disposal. The bulk of the $\mathrm{LiCl}-\mathrm{Li}_{2} \mathrm{O}$ molten salt remains in the electrolytic reduction cell and is reused indefinitely.

The silver impregnated zeolite containing the iodine released during fuel chopping can be combined with the ceramic waste form prior to its disposal.

\section{FR FLOWSHEET}

The conceptual flowsheet for the treatment of used metallic fast reactor fuel is shown in Figure 2. The centerpiece of the flowsheet is the electrorefining system

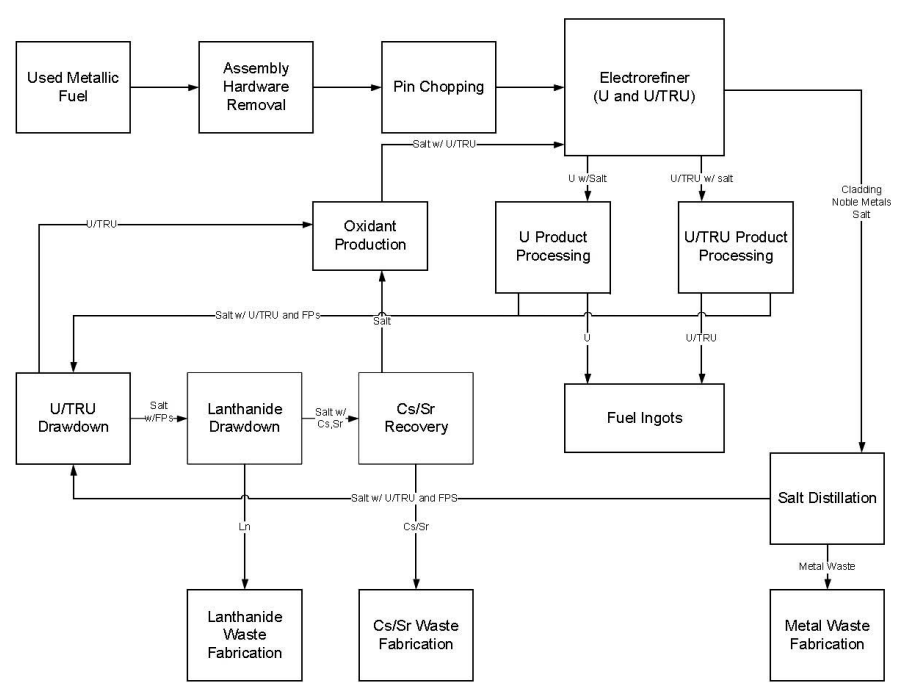

Fig. 2. Conceptual Flowsheet for the Treatment of Used FR Fuel. 
for uranium and U/TRU recovery. Products from the treatment process are similar to those from LWR fuel treatment and include uranium and a U/TRU alloy for recycle to FR fuel fabrication; a ceramic waste material destined for decay storage (i.e., $\mathrm{Cs} / \mathrm{Sr}$ product); and two high-level waste forms designed for geologic disposal lanthanide borosilicate glass and a metal alloy, which contains Tc and other noble metals.

The process descriptions provided in the section on LWR fuel recycling are applicable to FR fuel recycling. The underlying chemistry of each of the treatment processes is not changed. In fact, each of the unit operations was intentionally designed for maximum flexibility so that treating different fuel types (e.g., LWR oxide and FR metal) is possible while still providing the desired products at the required quality. The unit operations are coupled so that as salt is removed from the electrorefining system (i.e., it adheres to the metal product), it is treated to remove the actinides and fission products, prepared for reuse and recycled to the electrorefiner.

The obvious difference in the FR flowsheet is that the electroreduction process is not needed to convert the fuel to metallic form. Fission gas released during the fuel chopping and the electrorefining process must be collected by the off-gas system. In addition, the $\mathrm{Cs} / \mathrm{Sr}$ removal process occurs at the back end of the process after the lanthanide drawdown because the alkali and alkaline earth elements partition to the salt phase during electrorefining. They are removed after the lanthanides because the alkali and alkaline earth fission products form chlorides that are more thermodynamically stable than the actinide and lanthanide chlorides. Similarly, iodine partitions to the salt phase as an alkali iodide during the electrorefining process and it too can be collected during the $\mathrm{Cs} / \mathrm{Sr}$ removal process and prepared for disposal.

\section{CONCLUSIONS}

Conceptual flowsheets have been developed for recycling actinides from used LWR and FR fuel. Flowsheet development was guided by past experience and a set of design principles for actinide recovery, non-proliferation, waste minimization and commercial viability that meet the general requirements of a modern fuel recycling system. These flowsheets, and hence the design principles, continue to guide our experimental pyroprocessing research and development activities.

Although extended discussion is beyond the scope of this paper, the technical maturity of the unit operations identified in each flowsheet varies from bench- to engineering-scale demonstrations. For example, the electrorefining, uranium processing and metal waste processing operations have all been demonstrated with used nuclear fuel at the engineering-scale. Other processes such as electrolytic reduction have been demonstrated at the engineering-scale with simulated fuel and the benchscale with irradiated LWR fuel. Yet other processes such as U/TRU co-deposition have been demonstrated, using $\mathrm{U}$, and TRUs (Pu and $\mathrm{Np}$ ), at the bench-scale.

In general, high actinide recovery efficiency is achieved by two operations within the flowsheet. The bulk of the actinides are recovered in the electrorefining process and prepared for use in fuel fabrication after separation of the recovered metals from the adhering salt layer. This salt is not discarded but further treated by electrolysis to extract the actinides prior to removal of the fission products and recycle to the process. Actinides recovered by electrolysis can be recycled to the electrorefiner as oxidant (as shown in the flowsheet) unless they are of sufficient purity for direct discharge to fuel fabrication. This approach achieves minimal actinide loss without resorting to extensive recycle or polish streams.

Non-proliferation features of the flowsheet not only include the production of a co-deposited U/TRU product but the ability to monitor the salt composition and process operations by electroanalytical and spectroscopic methods. Since the main unit operations achieve separations using electrochemical methods, many complementary electroanalytical techniques such as voltammetry are available to monitor the actinide content in the salt phase as well as process operating conditions such as deposition potentials. These techniques provide on-line real-time sensors that provide a window into the process to detect materials diversion as well as data relevant to materials accounting.

Waste minimization is achieved through the use of electrochemical processes that do not require extensive quantities of chemical reagents or the associated reagent recycle streams. Instead, the process medium (i.e., electrolyte salt) is treated to remove fission products and polish residual actinides prior to recycle to the electrorefining operation. In addition, collecting the bulk of the fission products as metals and producing tailored waste forms also reduces the amount of process waste. For example, encapsulating the lanthanides in a lanthanide borosilicate glass allows for up to $50 \mathrm{wt} \%$ lanthanide loading in the waste form thus enhancing the capacity of a repository. Similar enhancements are also achieved with the metal waste form.

Finally, process commercial viability is addressed through the simplicity of the unit operations, and lack of extensive recycle streams. Electrochemical systems are common industrial operations that possess features that allow for remote maintenance. The process chemistry is robust and features can easily be designed into the electrochemical cells to recover from process upsets. Scale-up of the electrochemical equipment is directly proportional to electrode surface area and the capacity of the power systems. Power and control systems can be 
external to the hot-cell facility and easily replaced. To facilitate maintenance, those components inside the facility such as electrodes can be designed in a plug-andplay fashion. In addition, components such as fuel baskets or product collectors that are passed from one operation to the next can be of a universal design to enhance process simplicity and maintainability.

\section{ACKNOWLEDGEMENTS}

This work is supported by the U.S. Department of Energy, Office of Nuclear Energy, Fuel Cycle Research and Development Program. The submitted manuscript has been created by UChicago Argonne, LLC, Operator of Argonne National Laboratory ("Argonne"). Argonne, a U.S. Department of Energy Office of Science laboratory, is operated under Contract No. DE-AC0206CH11357. The U.S. Government retains for itself, and others acting on its behalf, a paid-up nonexclusive, irrevocable worldwide license in said article to reproduce, prepare derivative works, distribute copies to the public, and perform publicly and display publicly, by or on behalf of the Government.

\section{REFERENCES}

[ 1 ] C.E. Stevenson, “The EBR II Fuel Cycle Story," American Nuclear Society, LaGrange Park, IL USA (1987).

[2] R.K. Steunenberg, R.D. Pierce and L. Burris, "Pyrometallurgical and Pyrochemical Fuel Processing," Progress in Nuclear Energy Series III, Process Chemistry, 461 (1969).

[ 3 ] C.E. Till, Y.I. Chang and W.H. Hannum, "The Integral Fast Reactor - An Overview," Progress in Nuclear Energy, 31, 1-2, 3 (1997) and references therein.

[4] National Research Council, "Electrometallurgical Techniques for DOE Spent Fuel Treatment: Final Report," National Academy Press, Washington, DC (2000).

[5] K. Gourishankar, L. Redey and M.A. Williamson, "Electrochemical Reduction of Metal Oxides in Molten Salts," Light Metals 2002, TMS, 1075 (2002).

[6] L.A. Barnes and M.A. Williamson, "Developments in Electrolytic Reduction: Effect of Rare Earth Oxides," 2008 International Pyroprocessing Research Conference, Jeju Island, Republic of Korea, August 2008.

[ 7 ] A.F. LaPlace, J. Lacquement, J.L. Willit, R.A. Finch, G.A. Fletcher and M.A. Williamson, "Electrodeposition of Uranium and Transuranics $(\mathrm{Pu})$ on Solid Cathodes," Nuclear Technology, Vol. 163, 366 (2008). 